\title{
Effects of orientin and vitexin from Trollius chinensis on the growth and apoptosis of esophageal cancer EC-109 cells
}

\author{
FANG AN $^{1}$, SHUHUA WANG ${ }^{2}$, QINGQING TIAN ${ }^{2}$ and DENGXIANG ZHU ${ }^{2}$ \\ ${ }^{1}$ Graduate Faculty; ${ }^{2}$ Department of Pharmacy, Hebei North University, Zhangjiakou, Hebei 075000, P.R. China
}

Received October 6, 2014; Accepted July 7, 2015

DOI: 10.3892/ol.2015.3618

\begin{abstract}
Orientin and vitexin are the monomers of total flavonoids in Trollius chinensis Bunge. Orientin and vitexin have the same chemical constitution. Modern studies on pharmacology have indicated that the total flavonoids of this plant have antitumor actions. The aim of the present study was to investigate the effects of orientin and vitexin on the growth and apoptosis of EC-109 cells, to investigate the expression of p53 and B-cell lymphoma (bcl-2), and to discuss the associated antitumor activity, in vitro. This data provides experience for the basis of the selection and structure-activity associations of antineoplastic agents, and analysis of the efficacy of the total flavonoids in Trollius chinensis. In this study, EC-109 cells in the logarithmic growth phase were treated with different concentrations of orientin and vitexin. The inhibitory effect on cell growth and proliferation was detected by MTT method. Cell nuclei were assayed by the cell death detection using Hoechst 33258 staining, cell apoptosis was detected by DNA agarose gel electrophoresis, and the apoptosis rate of the EC-109 cells was examined using an Annexin V-fluorescein isothiocyanate/propidium iodide double-labeled technique of flow cytometry (FCM). The protein expression of p53 and bcl-2 in the EC-109 cells was detected by FCM. Orientin and vitexin exhibited marked inhibitory effects on the proliferation of the EC-109 cells. The inhibition rate increased with the increase in concentration and reaction time, and orientin and vitexin were able to induce the apoptosis of the EC-109 cells. The gene expression levels of p53 and bcl-2 were upregulated and downregulated, respectively. Additionally, the antitumor effects of orientin were stronger than that of vitexin using the same concentration. These experimental findings indicated that orientin and vitexin engender antitumor effects that may be associated with the regulation of the apoptosis-related gene expression of p53 and bcl-2. Therefore, orientin and vitexin may serve as therapeutic agents for the treatment of esophageal cancer.
\end{abstract}

Correspondence to: Mr. Fang An, Graduate Faculty, Hebei North University, 11 South Diamond Road, Zhangjiakou, Hebei 075000, P.R. China

E-mail: wangshyh@126.com

Key words: orientin, vitexin, EC-109, apoptosis

\section{Introduction}

Esophageal cancer is a malignant tumor, and is the leading cause of morbidity and mortality in certain areas of China. The prognosis of patients with esophageal carcinoma is poor, with a 5-year overall survival rate of $\sim 10 \%$ for advanced esophageal cancer (1). In order to control the spread of cancer and to find an effective integrated therapeutic treatment, the clinical treatment of esophageal cancer using potential novel drugs has become a focus of research attention, although surgical treatment remains the primary therapy $(2,3)$. Recently, a number of novel drugs, including taxol, oxaliplatin and irinotecan, have been used for the treatment of esophageal cancer, providing impetus for the research and development of novel antitumor agents.

The dried flowers of Trollius chinensis Bunge have been used as a traditional Chinese medicine for a long time. The plant grows widely throughout Southwest, Northwest and Northeast china (4). The plant is used to reduce swelling and promote good eyesight, and is clinically approved for antibacterial and antiviral treatments (5-7). Previous studies have shown that the total flavonoids in Trollius chinensis possess anticancer activity, however, the mechanisms have not been elucidated (8-10). Orientin and vitexin are the monomer components of total flavonoids in Trollius chinensis. The content of orientin and vitexin, which belong to the flavone C-glycoside class, is higher in the flavone of Trollius chinensis (11-13). Orientin possesses antithrombus and antioxidant abilities, and protects against myocardial ischemic-anoxic injuries (14-16). Vitexin has strong antioxidant and antiviral effects $(17,18)$. Orientin and vitexin have the same chemical constitution as cyanidenon and apigenin, which are anticancer agents (Fig. 1) (19). As such, we hypothesized that orientin and vitexin have marked antitumor capacities. Flavone C-glycosides have stronger anti-inflammatory effects in vitro than flavonoids. Moreover, the structure of flavone C-glycosides affects their anti-inflammatory activity (20). The difference between orientin and vitexin is that orientin has a phenolic hydroxyl group at the $3^{\prime}$ of the B ring (21); it is therefore worth considering how this architectural difference affects the antineoplastic activity of orientin and vitexin. There are currently no studies regarding the effects of orientin and vitexin on the induction of apoptosis in esophageal cancer cells in vitro. In the present study, EC-109 cells were used for the comparison of the effects of orientin and vitexin in a broad attempt to investigate their antitumor capacities. 


\section{Materials and methods}

Reagents. Wild Trollius chinensis was identified by Professor Shulan Ma, who works in the Institute of Materia Medica (Hebei North University, Zhangjiakou, Hubei, China). Dried flowers of Trollius chinensis were collected from Guyuan, Zhangjiakou, Hebei, China.

First, a high-performance liquid chromatography method (Agilent 1100 high performance liquid chromatograph; Agilent Technologies Inc., Santa Clara, CA, USA) was developed for the determination of the purity of orientin and vitexin. The column was a Hypersil BDS C18 (4.6x150-mm, 5- $\mu \mathrm{m})$ column (Thermo Fisher Scientific Inc., Waltham, MA, USA) that used an acetonitrile:acetic acid (15:85) solution as the mobile phase and a flow rate of $1.0 \mathrm{ml} / \mathrm{min}$. The column temperature was set to $30^{\circ} \mathrm{C}$. The detection wavelength was $340 \mathrm{~nm}$. A preparative high-performance liquid chromatography method was also established for purifying the orientin and vitexin. The column was a ZORBAX SB-C18 (21.2x250-mm, 7- $\mu \mathrm{m})$ column (Agilent Technologies Inc.) that used an acetonitrile:acetic acid (15:85) solution as the mobile phase and a flow rate of $20 \mathrm{ml} / \mathrm{min}$. The column temperature was set to $25^{\circ} \mathrm{C}$. The detection wavelength was $340 \mathrm{~nm}$. A fraction was collected based on the peak, with a minimum threshold of 2.2. Nuclear magnetic resonance spectroscopy was used by the Chinese Academy of Sciences Nuclear Magnetic Resonance Institute, Beijing, China) to identify the structure of orientin and vitexin. High-performance liquid chromatography was used for the quantitative analysis of orientin and vitexin. The purities of orientin and vitexin were found to be 98.9 and $98.6 \%$, respectively (Fig. 2).

MTT was purchased from Shanghai Mazhijia Corporation (Shanghai, China). The Hoechst Staining kit was purchased from Beyotime Institute of Biotechnology (Shanghai, China) and the Annexin-FITC Apoptosis Detection kit was manufactured by Jingmei Biological Engineering Corporation (Shenzhen, China). Agarose and the 100-bp DNA marker were obtained from Beijing Liuhetong Corporation (Beijing, China). Fetal bovine serum was manufactured from Hangzhou Sijiqing Bio-engineering Material Co., Ltd. (Hangzhou, China). Fluorescein isothiocyanate (FITC)-p53 and phycoerythrin-B-cell lymphoma-2 (PE-bcl-2) were purchased from BD Biosciences (Franklin Lakes, NJ, USA). Trypsin was bought from the North China Pharmaceutical Group (Shijiazhuang, China) and dimethyl sulfoxide (DMSO) was obtained from Beijing Chemical Reagent Factory (Beijing, China). The EC-109 cells were purchased from the National Cancer Institute of Beijing (Beijing, China).

Cell culture and grouping. Esophageal cancer EC-109 cells were grown in RPMI-1640 medium (Gibco Life Technologies, Carlsbad, CA, USA), the $\mathrm{pH}$ of which was adjusted to 7.2-7.4 with sodium bicarbonate, and supplemented with $10 \%$ fetal calf serum (Hangzhou Sijiqing Biological Engineering Material Co., Ltd.) and gentamycin (100 U/ml; North China Pharmaceutical Group) in an incubator with $5 \% \mathrm{CO}_{2}$ at $37^{\circ} \mathrm{C}$ under saturated humidity. Subsequent to being cultured for $24 \mathrm{~h}$, the cells were observed under a reverse-phase microscope (Eclipse Ti-U; Nikon, Tokyo, Japan). Clear cells adhering to the wall appeared to exhibit a spindle shape, which indicated
A

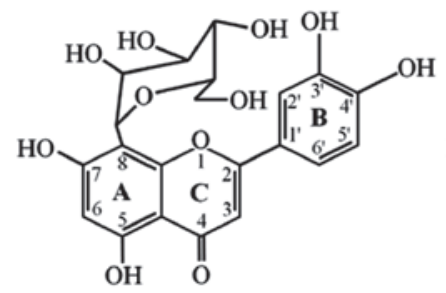

B

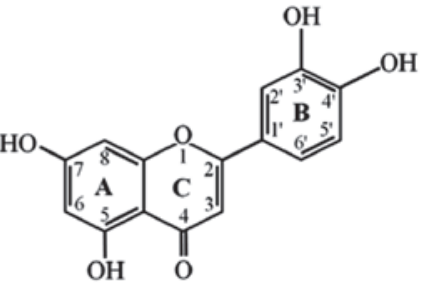

C

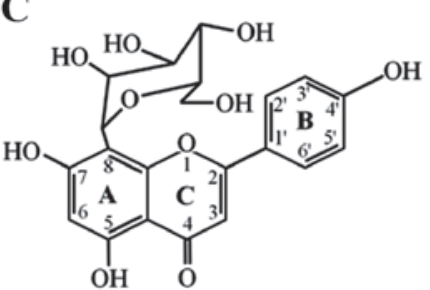

D

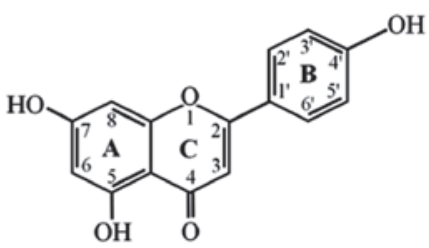

Figure 1. Chemical structures of orientin and vitexin. The chemical structures of orientin (A) and vitexin (C) are similar to those of cyanidenon (B) and Apigenin (D), which are strong anticancer. All of these structures have an $\mathrm{A}$ ring and a $\mathrm{B}$ ring.
A

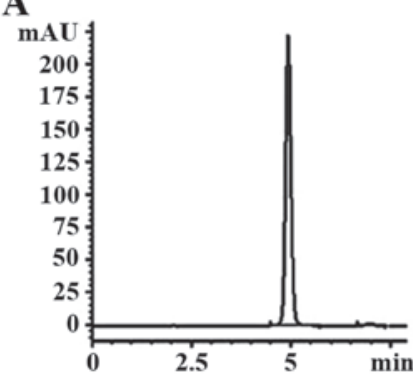

C

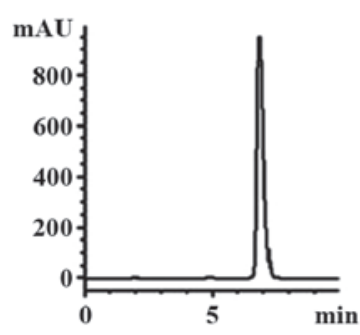

B

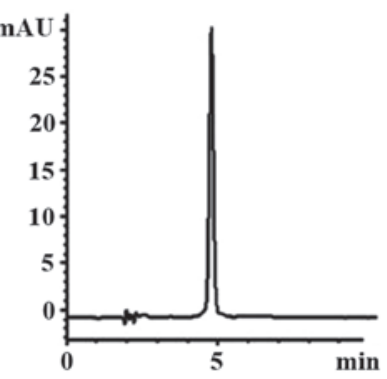

D

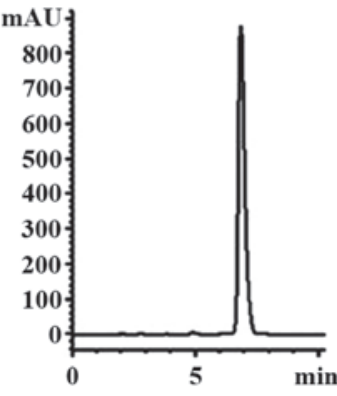

Figure 2. Chromatographic analysis of orientin and vitexin. Compared with standard orientin (A), the purity of the orientin sample (B) was $98.9 \%$. Compared with standard vitexin (C), the purity of the vitexin sample (D) was $98.6 \%$

they were in good condition. The cells were trypsinized with a $1: 3$ solution of $(0.25 \%)$ trypsin (North China Pharmaceutical Group) plus (0.02\%) EDTA (Beijing Chemical Reagent Factory), until the cells reached $80 \%$ confluence and were passaged. The cell cultures and experiments were performed in a sterile environment. Throughout the experiments, cells in the exponential growth phase were used.

The cells were split into four groups as follows: The orientin- and vitexin-treated groups (final concentrations of $5.0,10.0,20.0,40.0$ and $80.0 \mu \mathrm{M}$ for each group), a blank group (identical quantities of cell culture fluid to the 
Table I. Inhibitory effect of orientin and vitexin on EC-109 cells (mean \pm standard deviation; $\mathrm{n}=5$ ).

Inhibition rate of colony formation, $\%$

\begin{tabular}{|c|c|c|c|c|c|c|}
\hline \multirow[b]{2}{*}{ Concentration, $\mu \mathrm{M}$} & \multicolumn{2}{|c|}{$24 \mathrm{~h}$} & \multicolumn{2}{|c|}{$48 \mathrm{~h}$} & \multicolumn{2}{|c|}{$72 \mathrm{~h}$} \\
\hline & Orientin & Vitexin & Orientin & Vitexin & Orientin & Vitexin \\
\hline 5.0 & $5.23 \pm 0.12^{\mathrm{a}-\mathrm{c}}$ & $2.24 \pm 0.11^{\mathrm{a}-\mathrm{c}}$ & $10.82 \pm 0.23^{\mathrm{a}-\mathrm{c}}$ & $4.82 \pm 0.33^{\mathrm{a}-\mathrm{c}}$ & $18.38 \pm 0.16^{\mathrm{a}-\mathrm{c}}$ & $8.28 \pm 0.36^{\mathrm{a}-\mathrm{c}}$ \\
\hline 10.0 & $8.03 \pm 0.20^{\mathrm{a}-\mathrm{c}}$ & $3.67 \pm 0.26^{\mathrm{a}-\mathrm{c}}$ & $21.06 \pm 0.32^{\mathrm{a}-\mathrm{c}}$ & $8.06 \pm 0.32^{\mathrm{a}-\mathrm{c}}$ & $36.65 \pm 0.56^{\mathrm{a}-\mathrm{c}}$ & $14.65 \pm 0.56^{\mathrm{a}-\mathrm{c}}$ \\
\hline 20.0 & $14.35 \pm 0.43^{\mathrm{a}-\mathrm{c}}$ & $8.35 \pm 0.44^{\mathrm{a}-\mathrm{c}}$ & $30.02 \pm 0.88^{\mathrm{a}-\mathrm{c}}$ & $15.02 \pm 0.30^{\mathrm{a}-\mathrm{c}}$ & $48.78 \pm 0.58^{\mathrm{a-c}}$ & $26.70 \pm 0.52^{\mathrm{a}-\mathrm{c}}$ \\
\hline 40.0 & $20.43 \pm 0.51^{\mathrm{a}-\mathrm{c}}$ & $13.43 \pm 0.51^{\mathrm{a}-\mathrm{c}}$ & $36.90 \pm 0.67^{\mathrm{a}-\mathrm{c}}$ & $21.90 \pm 0.60^{\mathrm{a}-\mathrm{c}}$ & $51.04 \pm 0.66^{\mathrm{a}-\mathrm{c}}$ & $33.04 \pm 0.63^{\mathrm{a}-\mathrm{c}}$ \\
\hline 80.0 & $34.08 \pm 1.16^{\mathrm{a}-\mathrm{c}}$ & $20.08 \pm 1.16^{\mathrm{a}-\mathrm{c}}$ & $44.60 \pm 1.45^{\mathrm{a}-\mathrm{c}}$ & $31.60 \pm 1.45^{\mathrm{a}-\mathrm{c}}$ & $58.80 \pm 1.11^{\mathrm{a}-\mathrm{c}}$ & $38.30 \pm 1.24^{\mathrm{a}-\mathrm{c}}$ \\
\hline $0.2 \%$ DMSO & $0.66 \pm 0.23$ & $0.66 \pm 0.23$ & $0.58 \pm 0.15$ & $0.58 \pm 0.15$ & $0.49 \pm 0.44$ & $0.49 \pm 0.44$ \\
\hline
\end{tabular}

${ }^{\mathrm{a} C}$ Comparisons between orientin at different concentrations at the same time, $\mathrm{P}<0.01$; ${ }^{\mathrm{b}}$ comparisons between five repetitions of orientin and vitexin treatments of the same concentrations for different time periods, $\mathrm{P}<0.01$; $^{\mathrm{c}}$ comparison between orientin and vitexin of the same concentrations for different time periods, $\mathrm{P}<0.01$.

drug-treated group), and a solvent control group (cell culture fluid containing DMSO, with a final concentration of $0.2 \%$ ).

Growth inhibition assay. The effect of orient and vitexin on the growth and survival of the EC-109 cells was determined by the MTT assay. Orientin and vitexin are insoluble in water. Using DMSO as the cosolvent, orientin or vitexin were diluted with culture medium. The cells were observed after exposure to the drugs at different concentrations for 24,48 and $72 \mathrm{~h}$. The experiments for the two control groups and the two drug-treated groups were repeated 5 times without exception. Exponentially growing EC-109 cells were harvested, counted and the cell concentration adjusted. A total of $100 \mu \mathrm{l}$ single cell suspension was plated at $5 \times 10^{4}$ cells per well in 96-well plates for $24 \mathrm{~h}$. Following cell adherence, the medium in the plates was substituted with $100 \mu$ l of each drug at the different concentrations, diluted with culture fluid according to grouping. An equal amount of culture liquid was added to the blank control group, whereas an equal amount of culture liquid supplemented with DMSO to a final concentration of $0.2 \%$ was added to the solvent control group. Following incubation for 24,48 or $72 \mathrm{~h}, 20 \mu \mathrm{l}$ of MTT stock solution was added to each well and the plates were further incubated for $4 \mathrm{~h}$ at $37^{\circ} \mathrm{C}$. A microplate reader (Spectra Max M2; Molecular Devices Corporation, Silicon Valley, CA, USA) was adopted to measure absorbance with a wavelength of $450 \mathrm{~nm}$. The average inhibition rate of the cancer cells treated with orientin and vitexin was calculated as follows: Inhibition rate $=$ (absorbance of blank control group - absorbance of drug group / absorbance of blank control group) x 100 .

Hoechst 33258 staining to observe EC-109 cellular morphology. A total of $900 \mu \mathrm{l}$ of EC-109 cells was seeded at $5 \times 10^{3}$ cells per well into 24-well flat-bottomed plates. Once incubated for $6 \mathrm{~h}$, the adherent cells was subjected to different concentrations of either orient or vitexin at 5.0, 20.0 or $80.0 \mu \mathrm{M}$. The blank group was not treated. Following incubation for $48 \mathrm{~h}$, the results were processed using an excitation wavelength of $340 \mathrm{~nm}$. Microscopy (ECLIPSE Ti-U; Nikon, Tokyo, Japan) was adopted for observation of the results and images were captured.
Agarose gel electrophoresis. The cells were plated in a 20-ml culture bottle at $1 \times 10^{6} / \mathrm{ml}$. Over time, the cells were treated with the drugs. The final concentration of orientin and vitexin was 5.0, 20.0 and $80.0 \mu \mathrm{M}$ in each group. The blank control group was also set up. The cells were harvested after a 48-h culture and washed three times using phosphate-buffered saline (PBS). The cells were transferred into 1.5-ml Eppendorf tubes and mixed with lysis buffer, prior to being agitated in a water bath at $70^{\circ} \mathrm{C}$ (two times for $15 \mathrm{~min}$ ). Centrifugation $(9,590.4 \mathrm{x} \mathrm{g})$ was performed and absolute ethyl alcohol was added into the supernatant to precipitate the DNA. After centrifugation $(9,590.4 \mathrm{x} \mathrm{g})$ of the solution obtained above, $20 \mu 1 \mathrm{TE}$ buffer (pH 7.4) was adopted to dissolve DNA. Agarose gel electrophoresis was performed using DYDP-31A agarose electrophoresis apparatus (Beijing LiuYi Instrument Factory, Beijing, China) in accordance with the manufacturer's instructions. Prior to the electrophoresis, RNase was added into the buffer obtained above. The $2 \%$ agarose gel electrophoresis last for $60 \mathrm{~min}$, and was observed, with images captured, using the gel imaging and analysis system (BioSpectrum AC system; UVP, Upland, CA, USA).

FCM to detect early apoptotic cells. The experimental group and the exposed time were the same as for the 'Agarose gel electrophoresis' section. Five parallel samples were set up for each group. The EC-109 cells $\left(1 \times 10^{6}\right)$ of the control and drug groups were harvested, centrifuged (374.6 x g) and the supernatant aspirated, prior to being washed twice with PBS.

Apoptosis was assessed using the Annexin V-FITC Apoptosis kit (Jingmei Biological Engineering Corporation) according to the manufacturer's instructions. Briefly, the cells were mixed with $10 \mu \mathrm{l}$ Annexin-V and $5 \mu \mathrm{l} \mathrm{PI}$, and kept away from the light for $20 \mathrm{~min}$. The supernatant was discarded and the cells were washed using PBS. The cells were then resuspended in $400 \mu \mathrm{l}$ PBS. FCM using FACS-Aria (BD Biosciences) was adopted to detect the early apoptotic rate.

FCM to detect 553 and bcl-2 protein expression. At a density of $1 \times 10^{6} / \mathrm{ml}$, EC-109 cells in the logarithmic growth phase were plated in a $20-\mathrm{ml}$ culture bottle. After a period of time, 
Table II. Effect of different concentrations of orientin and vitexin on EC-109 cell apoptosis (mean \pm standard deviation; $\mathrm{n}=3)$.

\begin{tabular}{lccc}
\hline & \multicolumn{3}{c}{ Apoptotic rate, $\%$} \\
\cline { 2 - 4 } Group & $5.0 \mu \mathrm{M}$ & $20.0 \mu \mathrm{M}$ & $80.0 \mu \mathrm{M}$ \\
\hline Orientin & $3.36 \pm 0.20^{\mathrm{a}-\mathrm{c}}$ & $7.21 \pm 0.34^{\mathrm{a}-\mathrm{c}}$ & $28.03 \pm 0.64^{\mathrm{a}-\mathrm{c}}$ \\
Vitexin & $1.68 \pm 0.15^{\mathrm{a}-\mathrm{c}}$ & $3.83 \pm 0.22^{\mathrm{a}-\mathrm{c}}$ & $12.38 \pm 0.42^{\mathrm{a}-\mathrm{c}}$ \\
Control $^{\mathrm{d}}$ & & $0.64 \pm 0.12$ & \\
\hline
\end{tabular}

${ }^{\mathrm{a} C}$ Compared with blank control, $\mathrm{P}<0.01$; ${ }^{\mathrm{b}}$ comparisons between orientin and vitexin at different concentrations, $\mathrm{P}<0.01$; ${ }^{\mathrm{c}}$ comparisons between orientin and vitexin at the same concentrations, $\mathrm{P}<0.01 .{ }^{\mathrm{d}} \mathrm{No}$ drug treatment: Cell culture fluid containing dimethyl sulfoxide, at a final concentration of $0.2 \%$.

the adherent cells was treated as appropriate for the blank control group, or with concentrations of 5.0, 20.0, 80.0 $\mu \mathrm{M}$ of orientin and vitexin, respectively. After $4 \mathrm{~h}$, the cells were harvested and $20 \mu \mathrm{l}$ FITC-p53 and PE-bcl-2 were added for $20 \mathrm{~min}$. The cells were then subjected to FCM.

Statistical analysis. The results are expressed as the mean \pm standard deviation, and data were tested by least significant difference tests using SPSS software version 16.0 (SPSS, Inc., Chicago, IL, USA). P $<0.05$ was used to indicate a statistically significant difference.

\section{Results}

Inhibition effect of orientin and vitexin in EC-109 cells. Experimental data from the present study showed that DMSO hardly had any effect on cell activity (Table I), with a maximum inhibition ratio of $<1 \%$, so the following experiments did not use a reagent control group. The results of the study confirm that the growth inhibition rate increased with increasing concentration of orientin and vitexin $(\mathrm{P}<0.01)$. With increased treatment time, the inhibition rates of orientin and vitexin at the same concentrations were significantly increased $(\mathrm{P}<0.01)$. The inhibition rate in the orientin-treated group was higher than that in the vitexin-treated group at the same concentrations $(\mathrm{P}<0.01)$ (Table I). Previous studies showed that the EC-109 inhibition ratio by Trollius chinensis flavonoids at a concentration of $0.793 \mathrm{~g} / 1$ for $24 \mathrm{~h}$ was $28.00 \%$ (7). The present study showed the inhibition ratio of orientin and vitexin in EC-109 cells to be 34.08 and $20.08 \%$, respectively, at $80.0 \mu \mathrm{M}(0.0359$ and $0.0356 \mathrm{~g} / \mathrm{l}$, respectively), which indicated that orientin and vitexin may be structural components that contribute to the efficacy of Trollius chinensis flavonoids. In addition, the anticancer activity of orientin and vitexin is superior to that of Trollius chinensis flavonoids.

Hoechst 33258 fluorescence tagging of DNA to observe nuclear morphometry. The blank control cells had uniform round- or oval-shaped nuclei with evenly distributed chromatin. Following exposure to ultraviolet light, the cells exhibited homogeneous blue fluorescence and areas of the cells at the

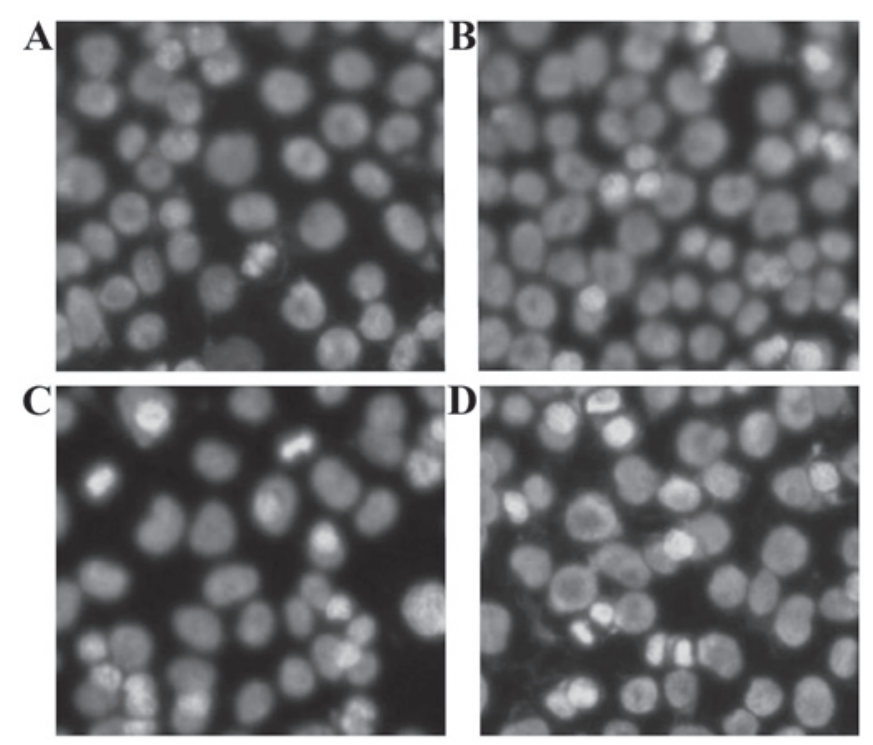

Figure 3. Morphological effect of vitexin on the nuclei of EC-109 cells (magnification, x400). (A) Control; and (B) 5.0, (C) 20.0 and (D) $80.0 \mu \mathrm{M}$ vitexin.

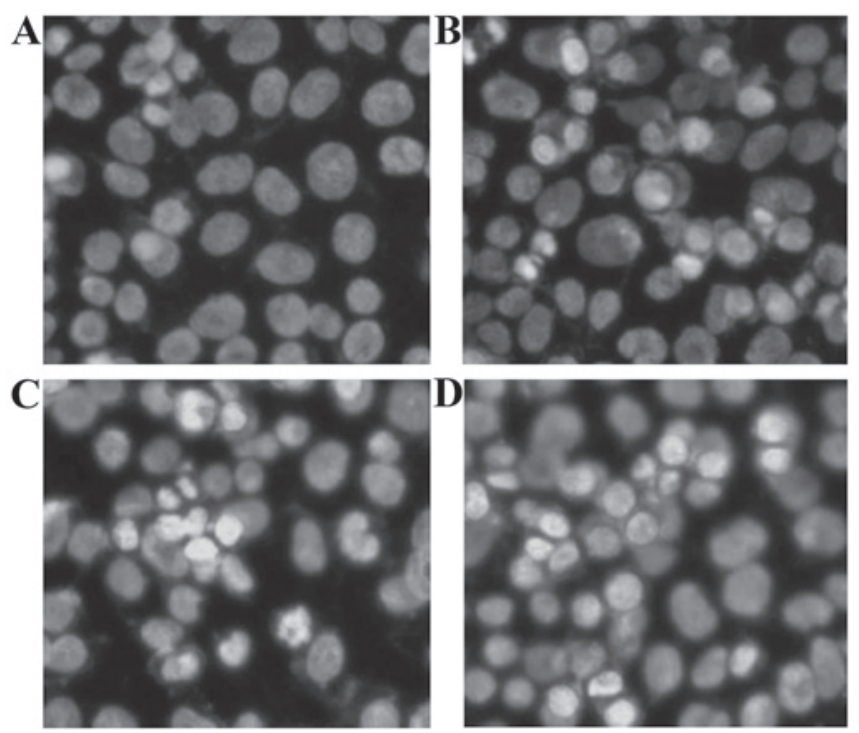

Figure 4. Morphological effect of orientin on the nuclei of EC-109 cells (magnification, $\mathrm{x} 400$ ). (A) Control, and (B) 5.0,(C) 20.0 and (D) $80.0 \mu \mathrm{M}$ orientin.

division stage could also be observed. The cells treated with orientin and vitexin showed typical apoptotic morphological changes. The apoptotic features were a shrunken cell body, brightly dyed nuclear chromatin, nuclear fragmentation and the formation of apoptotic bodies. The number of apoptotic cells increased gradually in a concentration-dependent manner. The activity of vitexin (Fig. 3) was lower than that of orientin (Fig. 4) at the same dose.

Effect of orientin and vitexin on the DNA of EC-109 cells. The results showed a marked difference in the DNA bands of control groups (lanes B and G) in comparison to those treated with orientin (lanes $\mathrm{C}-\mathrm{E}$ ) or vitexin (lanes H-J). The results showed that a DNA ladder could not be visualized in the blank control group, however, discrete DNA bands were observed in the treated groups, particularly for the groups treated with 
Table III. Effects of p53 and bcl-2 on EC-109 cells treated with different concentrations of orientin and vitexin (mean \pm standard deviation; $n=5)$.

\begin{tabular}{|c|c|c|c|c|}
\hline \multirow[b]{2}{*}{ Concentration, $\mu \mathrm{M}$} & \multicolumn{2}{|c|}{$\mathrm{p} 53, \%$} & \multicolumn{2}{|c|}{ bcl-2, $\%$} \\
\hline & Orientin & Vitexin & Orientin & Vitexin \\
\hline 5.0 & $4.23 \pm 0.12^{\mathrm{a}-\mathrm{c}}$ & $2.95 \pm 0.14^{\mathrm{a}-\mathrm{c}}$ & $2.02 \pm 0.06^{\mathrm{a}-\mathrm{c}}$ & $3.48 \pm 0.07^{\mathrm{b}, \mathrm{c}}$ \\
\hline 20.0 & $12.35 \pm 0.43^{\mathrm{a}-\mathrm{c}}$ & $7.23 \pm 0.05^{\mathrm{a}-\mathrm{c}}$ & $1.03 \pm 0.07^{\mathrm{a}-\mathrm{c}}$ & $1.79 \pm 0.06^{\mathrm{a}-\mathrm{c}}$ \\
\hline 80.0 & $23.08 \pm 1.16^{\mathrm{a}-\mathrm{c}}$ & $14.06 \pm 0.07^{\mathrm{a-c}}$ & $0.17 \pm 0.05^{\mathrm{a}-\mathrm{c}}$ & $0.89 \pm 0.09^{\mathrm{a}-\mathrm{c}}$ \\
\hline Control $^{\mathrm{d}}$ & \multicolumn{2}{|c|}{$1.74 \pm 0.11$} & \multicolumn{2}{|c|}{$3.61 \pm 0.13$} \\
\hline
\end{tabular}

${ }^{\mathrm{a} C}$ Compared with blank control, $\mathrm{P}<0.01$; ${ }^{\mathrm{b}}$ comparisons between orientin and vitexin at different concentrations, $\mathrm{P}<0.01$; ${ }^{\mathrm{c}}$ comparisons between orientin and vitexin at the same concentrations, $\mathrm{P}<0.01$. ${ }^{\mathrm{N}} \mathrm{No}$ drug treatment: Cell culture fluid containing dimethyl sulfoxide, at a final concentration of $0.2 \%$.

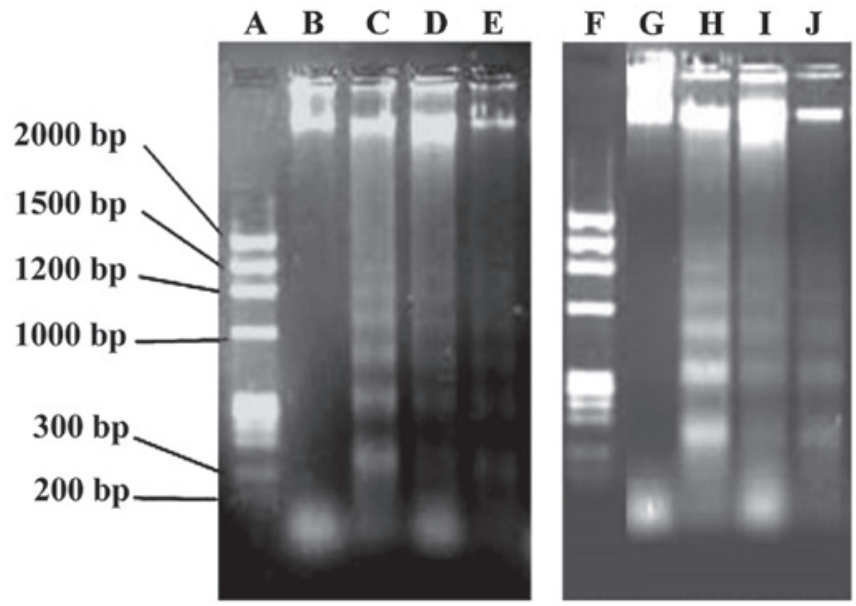

Figure 5. DNA electrophoretogram of EC-109 cells treated for $48 \mathrm{~h}$. (A and F) Marker; (B and G) control group; (C) 80.0,(D) 20.0 and (E) $5.0 \mu \mathrm{M}$ vitexin; and (H) 80.0, (I) 20.0 and (J) $5.0 \mu \mathrm{M}$ orientin.
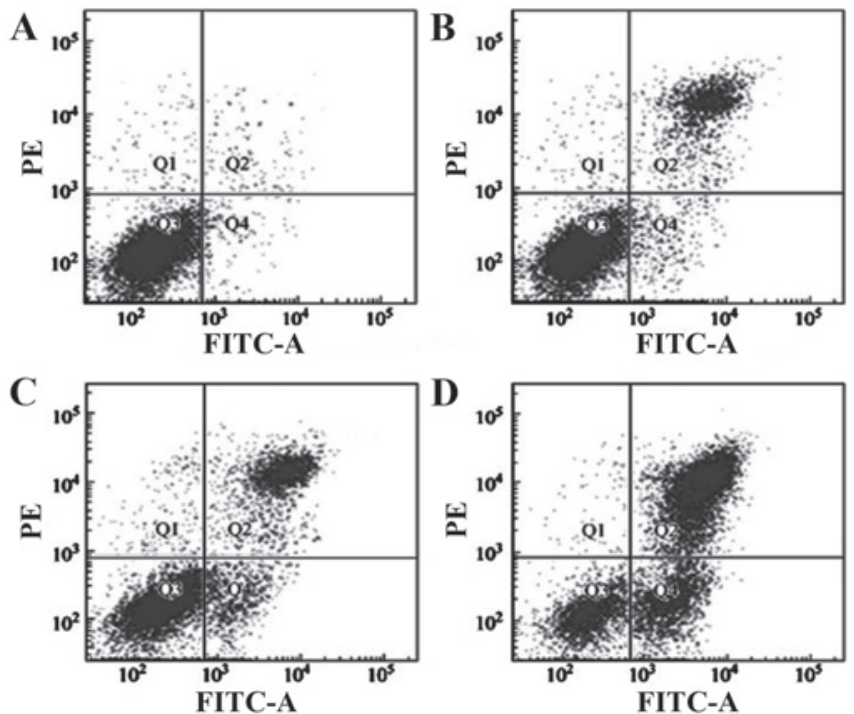

Figure 6. Flow cytometry detecting the effect of orientin on EC-109 cells. (A) Control; and (B) 5.0, (C) 20.0 and (D) $80.0 \mu \mathrm{M}$ orientin. PE, phycoerythrin; FITC-A, fluorescein isothiocyanate-Annexin V.

$80.0 \mu \mathrm{M}$ orientin or vitexin. The ladders in the groups exposed to 20.0 and $5.0 \mu \mathrm{M}$ of each agent were fuzzy and dark, however,
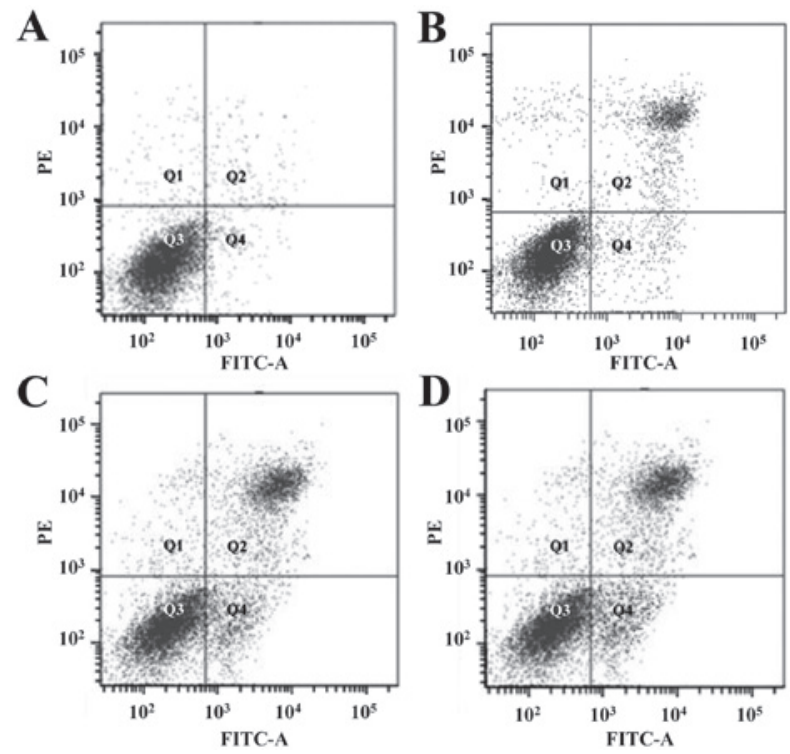

Figure 7. Flow cytometry detecting the effect of vitexin on EC-109 cells. (A) Control; and (B) 5.0, (C) 20.0 and (D) $80.0 \mu \mathrm{M}$ vitexin. PE, phycoerythrin; FITC, fluorescein isothiocyanate.

the bands were obvious. The DNA ladder of the cells exposed to orientin was brighter than that of the cells exposed to vitexin at the same concentrations, whereas the differences are not apparent (Fig. 5). These results indicated that orientin and vitexin induced cell apoptosis, in a dose-dependent manner, and the efficacy of orientin was higher than that of vitexin.

Effect of orientin and vitexin on EC-109 cell apoptosis rate. The Annexin V-FITC/PI double staining method was adopted and the detection results indicated that orientin and vitexin at different concentrations could induce the apoptosis of the EC-109 cells; the apoptosis rate was dose-dependent. The apoptosis rate differed significantly for the various concentrations used in the orientin-treated group $(\mathrm{P}<0.05)$. Similar results were found for the vitexin-treated group. The cell apoptosis rates showed a significant increase in the drug-treated groups compared with the control group $(\mathrm{P}<0.01)$. The EC-109 apoptotic rate following orientin treatment was $28.03 \%$, whereas following treatment with vitexin, this rate was $12.38 \%(\mathrm{P}<0.01)$ (Table II). The FCM detection results are presented in Figs. 6 and 7. 
Effect of orientin and vitexin on p53 and bcl-2 in EC-109 cells. When comparing EC-109 cells exposed to different concentrations of drugs for $48 \mathrm{~h}$ with the blank control group, the expression of p53 was significantly increased $(\mathrm{P}<0.01)$. Conversely, the expression of bcl-2 in the EC-109 cells was significantly decreased $(\mathrm{P}<0.01)$. These changes were dose-dependent. Compared with vitexin, orientin played significantly a greater role in affecting the expression of $\mathrm{p} 53$ and bcl-2 in the EC-109 cells $(\mathrm{P}<0.01$; Table III).

\section{Discussion}

This study shows that at concentrations ranging between 5.0 and $8.0 \mu \mathrm{M}$, orientin and vitexin inhibit esophageal cancer cell growth in a dose-and time-dependent manner. Analysis of the time-dose effect trends revealed that the high concentration group plays a significant role in the early time periods, and inhibition rate increased as concentration increased. However, the inhibition rate was not directly proportionate to the dose. At different time-points, the inhibition rate by orientin and vitexin at the same concentration showed time dependence. However, the inhibition rate was not directly proportional to time. When comparing the inhibition rate of $48 \mathrm{~h}$ to that of $24 \mathrm{~h}$, there are significant differences between the two. The same is true for 48 and $72 \mathrm{~h}$. The results indicated that $48 \mathrm{~h}$ is the best timing for research on the early apoptosis of EC-109. Hence, the drug exposure time was fixed at $48 \mathrm{~h}$ in the following three experiments of cell apoptosis detection.

In the early stages of cell apoptosis, the degradation of DNA in the nucleus was under control, forming different lengths of nucleic acid fragments; however, necrocytosis and DNA degradation occurred in the later stages of apoptosis. Thus, the emergence of a DNA ladder signified apoptosis. When adopting the agarose gel electrophoresis and Hoechst 33258 staining methods, the results showed that orientin and vitexin could inhibit EC-109 cell growth and induce apoptosis, which was concentration-dependent. FCM, which is not only used for quantitative analysis but also for discrimination of necrotic cells, is an authoritative testing method for analyzing cell apoptosis (22). When adopting FCM, the present study found that EC-109 cell apoptosis, induced by orientin and vitexin, is dose-dependent. However, it is worth noting that the number of dead cells increased as apoptosis increased, as shown in the FCM detection image, which awaits further research.

The concrete mechanism of cell apoptosis involves a series of complex gene regulatory actions. In a previous study (23), genes in cells relevant to apoptosis were divided into two types: The apoptosis genes and the anti-apoptosis genes. Drug-induced cell apoptosis and necrosis was found to be regulated by one or more genes. Oncogenes existing in normal cells take part in normal cell growth, differentiation and metabolism. Anti-oncogenes are genes with the potential capacity to inhibit carcinogenesis and could inhibit cancer cell growth (24). Oncogene and tumor suppressor genes play a role in tumor occurrence and development; oncogenes could promote cancer cell proliferation, resulting in tumors, while tumor suppressor gene could induce cancer cell apoptosis, eliminate the cancer cells (25). The present experimental results showed that orientin and vitexin upregulated oncogene p53 expression and downregulated cancer-promoting gene bcl-2 expression, and then induced apoptosis in the EC-109 cells.

In conclusion, the present study showed that orientin and vitexin could inhibit cell growth and induce an early apoptotic state in EC-109 cells. The effect of orientin was greater than that of vitexin at the same concentration, which may or may not be associated with the hydroxyl groups at the 3 ' and 4' of the $\mathrm{B}$ ring in orientin compared with the single hydroxyl group at the 4 ' of the $\mathrm{B}$ ring in vitrexin. It follows that orientin and vitexin as flavone $\mathrm{C}$-glycosides are likely to be a novel type of esophageal cancer treatment, with good research and clinical application prospects.

\section{Acknowledgements}

This study was financially supported by the Major Scientific Projects of Hebei North University (grant no. ZD1314), and was partly supported by the Technology Bureau of Zhangjiakou (grant no. 11110015D).

\section{References}

1. Zhang XG: Risk factors and prevention research progress of esophagus cancer. World Chin J Dig 17: 670-680, 2009 (In Chinese).

2. Li XK and Fan QX: The research progress of esophageal cancer drug therapy. World Chin J Dig 35: 3482-3487, 2012 (In Chinese).

3. Kelsen D, Ajani J, Ilson D, Daugherty K and Pazdur R: A phase ii trial of paclitaxel (Taxol) in advanced esophageal cancer: Preliminary report. Semin Oncol 5 (Suppl 8): 44-48, 1994.

4. Li LQ: The geographical distribution of buttercup family of Trollius chinensis. Acta Phytotaxonomica Sinica 33: 535-537, 1995 (In Chinese).

5. Li YL, Ye SM, Wang LY and Cen YZ: Isolation and biological activity of proglobeflowery acid from Trollius chinensis Bunge. J Jinan Univ 23: 124-126, 2002 (In Chinese).

6. Shen ZP: Traditional Chinese medicine pharmaceutical research and application of Trollius chinensis. Lishizhen Med Mater Med Res 11: 1110-1113, 2000 (In Chinese).

7. Su LJ, Tian $\mathrm{H}$ and Ma YL: Trollius chinensis Bunge ethanol-extraction objects in experimental study of antiviral effect. Chin Herb Med 38: 1062-1064, 2007 (In Chinese).

8. Sun L, Liu F, Liu H, Luo Q and An F: The effects of Trollius flavonoids on human breast cancer cells. J Chin G 29: 1098-1099, 2009 (In Chinese).

9. Sun L, Cheng JZ, Luo Q, Zhang XC, Bai XM and An F: Effects of Trollius flavonoids on proliferation of K562, HeLa, Ec-109 and NCI-H446 tumor cells. Med J Zhengzhou Univ 44: 981-983, 2009 (In Chinese).

10. Sun L, Luo Q, Zhang L, Hao XQ, Liu H, Tian JM and An F: Effects of Trollius flavonoids on growth and apoptosis of A549 cells. J Chin G 31: 82-83, 2011 (In Chinese).

11. Su LJ, Wang H and Su ZW: Chemical component and pharmacology of Trollius. World Notes Plant Med 20: 14-16, 2005 (In Chinese).

12. Kang SW and Yu YF: The research on Trollius chemical component. Chin Herb Med 15: 7-9, 1984 (In Chinese).

13. Liu LJ, Wang XK and Kuang HX: Study on the chemical composition of leaves and stalks of Trollius macropetalus. Yao Xue Xue Bao 27: 837-840, 1992 (In Chinese).

14. Fu XC, Li SP, Wang XG and Yan Z: Research on antithrombotic effect of orientin. China Pharm 17: 1292-1293, 2006 (In Chinese).

15. Yang GD, Rao N and Tian JM: The study on antioxidant effect of orientin and vitexin from Trollius chinensis. Lishizhen Med Mater Med Res 22: 2172-2173, 2011 (In Chinese).

16. Fu XC, Wang X and Zheng H: The protective effect of orientin on ischemic and anoxic myocardial cells. J Sou Med Univ 127: 1173-1175, 2007 (In Chinese).

17. Yang GD, Rao N, Tian JM, An F and Wang SH: Study on antioxidation of orientin and vitexin from Trollius chinensis. Lishizhen Med Mater Med Res 22: 2172-2173, 2011 (In Chinese). 
18. Zhang X: Research progress of vitexin pharmacologic action. China Med Hed 10: 35-42, 2013 (In Chinese).

19. Chang W: The structure-activity relationship and ROS related mechanism of anti-cancer effect of flavonoids. Chongqing: TMMU, 2008 (In Chinese).

20. Wu XA, Qin F and Du MQ: Quantitative structure and anti- inflammatory activity relationship preliminary discussion of flavone- $C$ glycosides. Lishizhen Med Mater Med Res 23: 632-633, 2012 (In Chinese).

21. Wu XA, Qing F and Du MQ: The QSAR study on anti-inflammatory activities of C-glycosy flavones. Lishizhen Med Mater Med Res 23: 632-633, 2012 (In Chinese).
22. Lamm GM, Steinlein P, Cotten M and Christofori G: A rapid, quantitative and inexpensive method for detecting apoptosis by flow cytometry in transiently transfected cells. Nucleic Acids Res 23: 4855-4857, 1997.

23. Lu W: The mechansim of shikonin-induced apoptosis in MCF-7 breast cancer. Jilin Univ: 17-23, 2013 (In Chinese).

24. Peng L, Qi FL and Yin YH: New approach of oncotherapy - Chinese medicine ingredients induced differentiation of malignant cell. B Bio 37: 8-11, 2002 (In Chinese).

25. EI-Aneed A: Current strategies in cancer gene therapy. Eur J Pharm 498: 1-8, 2004. 